\section{Consumers' preference and willingness to pay for graded beef in Polokwane municipality, South Africa}

Florah L. Makweya, Isaac B. Oluwatayo

Department of Agricultural Economics and Animal Production, University of Limpopo, Polokwane, South Africa

\section{Abstract}

Consumers around the world are progressively becoming more concerned and aware about food standards, quality and safety issues. The purpose of this study was to determine consumers' preference regarding safe and quality beef and willingness to pay (WTP) for graded beef in Polokwane municipality, Limpopo Province, South Africa. The research surveyed 150 consumers using a structured questionnaire to collect data on consumer characteristics and responses to different bid levels for graded beef. Analytical methods were descriptive statistics, Likert scales, contingent valuation method to evaluate respondents' mean WTP for graded beef and logit model to determine the dependence of WTP on consumers' socioeconomic characteristics. Results showed that consumers prefer their beef tender, with less fat and bones and labelled with price, grade/class, size or quantity of the product and lastly quality inspection or certification indicator. Over half of the respondents $(53 \%)$ were aware of grading or classification systems. The results further revealed that most respondents are willing to pay an increase of $16.04 \%$ over the current price for beef. This could be an opportunity for investments in beef label industry. Consumer characteristics including age, income, gender and household size significantly influenced WTP for graded beef in Polokwane Municipality. Marketing strategies considered by beef product investors should target young, female and wealthier consumers. Grading with respect to quality attributes would make beef sales at differentiated prices possible. This will eventually enhance sales volume and returns for all stakeholders along the value chain.

\section{Introduction}

The global market for animal food products and the demand for meat based sources of protein have increased signifi- cantly throughout the world. Meat has become the fastest growing agricultural product worldwide due to high consumption rates and large quantities of trade (Schutte, 2006). Beef represents an important livestock commodity in the international market for animal based food products. Growth in the international market for beef products has endorsed significant expansion of cattle operations throughout the world (Hall, 2012).

In spite of the nutritional value beef constitutes to the diets of most consumers, its consumption has turned out to be a very questionable issue. From one viewpoint, beef represents a valuable source of proteins, vitamins (A, B6, B12, D and E), biologically utilizable contents of minerals (Calcium, Phosphorous, Iron, and Magnesium) and micronutrients that are contributing to consumers' health throughout life (Markiewicz, 2010; Mabhera, 2015). Hence, the dietary worth has been vital to convey the medical advantages of red meat to buyers. Then again, red meat has been highly topical in the past two decades because of the arising innovations in the meat industry the developments in the market have tarnished the positive image of the value of meat (Van Wezemael et al., 2010).

Consumers' all over the world have turned out to be progressively worried about food borne diseases, personal health and are aware of the quality of food they consume (Van Wezemael et al., 2010). On another perspective, Kumm (2002) iterated that consumers are increasingly expressing concerns on how the production, processing and transportation of meat is done, particularly since producing beef is resource intensive and aggressive on the environment. This has led consumers to seek for beef which is of high-value, safer, healthier and produced in an ecological and ethical harmony with the environment. Radman et al. (2005) explains that these structural modifications in consumer trends result from economic and social factors such as modern lifestyles, increased education, rising incomes and globalization.

As South Africa makes its transition to a developed economy, a percentage of its population is becoming wealthier, demanding more goods, being more health cautious and eating foods of higher quality standards (Vermeulen and Biénabe, 2010). This trend has emerged in developed countries and is now increasingly common in growing urban areas of developing and transitional countries (Dhivya, 2014). Populations residing in the urban areas of this developing country are increasingly becoming more aware of food safety issues and this requires
Correspondence: Isaac Busayo Oluwatayo, Department of Agricultural Economics and Animal Production, University of Limpopo, Private Bag X1106, Sovenga 0727, South Africa.

Tel.: +27.015.2683928.

E-mail: isaacoluwatayo@yahoo.com

Key words: Food safety, Graded beef, Preference, Polokwane, Quality, Willingness to pay.

Contributions: FLM contributed to the paper in terms of conceptualisation, data collection, analysis and interpretation of results. IBO contributed into the study concept, data analysis, results interpretation and editing of the final paper.

Conflict of interest: the authors declare no potential conflict of interest.

Funding: none.

Received for publication: 22 June 2018 Revision received: 4 October 2018.

Accepted for publication: 9 October 2018 .

This work is licensed under a Creative Commons Attribution-NonCommercial 4.0 International License (CC BY-NC 4.0).

(C) Copyright F.L. Makweya and I.B. Oluwatayo, 2019 Licensee PAGEPress, Italy

Italian Journal of Food Safety 2019; 8:7654 doi:10.4081/ijfs.2019.7654

manufacturers and sellers to be more concerned with production techniques, packaging, personal hygiene and other food safety requirements to understand what influences consumers' purchasing decisions and to meet their expectations (Uwamaliya, 2014).

Appearance of the product, convenience, shopping environment and product quality among others, are external factors that shape consumers' preference and choice in a market place. In an ideal world, consumers choose the package of food products that offers them the highest level of satisfaction, on the chance that they can absolutely decide the quality characteristics of those food items (Owusu-Sekyere, 2014). However, in cases where important information about product quality and safety is absent, consumers go through considerable challenges when choosing a product because they do not know risks associated with the product (Schroeter, 2005).

Food control measures (certification, traceability, etc.) in developed countries are serving to shape the potential of developing countries, especially for wealthier consumers residing in urban areas (Jaffee, 2004). Therefore, it is important for devel- 
oping countries to comply with international standards as it can help them to upgrade their capacity in regulation and monitoring of food value chains, as well as to participate in international markets (Uwamaliya, 2014).

\section{Problem statement}

Beef is an interesting case to analyse in SA regarding food safety as the beef industry contributes to food security and the growth of the economy. The beef industry in SA is not yet developed, compared with other industries it is challenged by growing demand surge, globalization, meeting consumers' changing expectations and increased complexities on the production of quality beef (Labuschagne et al., 2010). The South African carcass classification system assumes an imperative part in categorizing red meat carcasses to encourage price creation however, does not include any measure of meat quality. The system provides inadequate description of the meat quality characteristics and does not play a role at the consumer level, it clearly shows that it is strongly inclined towards meat sellers (Vermeulen et al., 2015).

The government has not yet set the required compulsory quality standards for beef in SA, the product sold on the market has no inspection indicators or labels to highlight information about product origin and quality characteristics. The country has experienced multiple health problems as a result of foodborne outbreaks, and this has placed most consumers in an uncertain state regarding beef safety and quality (Labuschagne et al., 2011).

A primary issue in the scandalous nature of meat is the manifestation of food safety cases. The meat sector, particularly the beef industry, is prone to many food scares including the recent case of Listeria in processed meat products, the bovine spongiform encephalopathy catastrophe, Salmonella, E.coli, dioxin (harmful residues) and genetic modifications (hormones) in the final products. These occurrences have caused financial losses, social interruptions and have damaged the reputation of the meat sector (Van Wezemael et al., 2010).

Consumers generally face considerable challenges in creating quality expectations, particularly for fresh meat because there is little or no information provided about the product. The certainty in the safety and suitability of food products, to some extent, originates from the viability of safety control measures such as certification, inspection and traceability on food products (Kimenju and De Groote, 2008). The information on labels is a significant tangible tool used by consumers to measure product quality or provide consumers with valuable quality indicators. However, South African consumers' views and usage on meat labels are largely unknown. According to Vermeulen et al. (2015) there is a definite need for the development and consumer testing of an appropriate front-of-pack labelling system to communicate quality and grading system on product labels. However, these control measures on product labels entails additional costs, which can increase the price of the labelled products (Uwamaliya, 2014).

The specific factors that influence South African consumers' preference regarding safe and quality beef and willingness to pay (WTP) for graded beef are not known because of absence of empirical literature. Labelling and traceability have been announced as a potential powerful vehicle for consumer reassurance. However, in practice, large gaps exist between reality and consumer perception of labels. This study intends to fill in the gaps by providing substantial and distinctive features required on labelled meat by consumers. More specifically, the following objectives are included: (1) to assess consumers' awareness on grading of beef; (2) to evaluate consumers' preference in relation to beef quality; (3) to determine consumers' willingness to pay for graded beef in Polokwane municipality; (4) to assess the relationship between consumers WTP and their socioeconomic characteristics.

\section{Literature review}

The significant imperatives to the development of the meat business are absence of the essential institutional structure, insufficient research considering biological potential for beef improvements, endemic and rising domesticated animal illnesses, repetitive dry seasons, decreasing animal hereditary qualities, poor promoting channels and static costs of livestock products (Bergevoet and Van Engelen, 2014). However, the absence of detailed communication to the consumer from the industry has been alluded as one of the fundamental issues of the meat industry (Soji et al. 2015). Meeting consumer needs for quality and providing them with dependable, unprejudiced information will empower the meat business to grow and to remain in business (Labuschagne et al., 2011).

Food safety can be considered an experience attribute, or in many cases a credence attribute that is why consumers unknowingly consume food that is unsafe (Latvala, 2010). Information asymmetry character- izes the market for products with credence attributes, meaning that the seller has more information about true product quality than the buyer (Sanderson and Hobbs, 2006) However, a single event of food safety incident (e.g. Listeria, E. coli, etc.) can damage the reputation of the industry and cause huge economic losses. Therefore, signs related with food are significant in communication media (Jongen and Meulenberg, 2005). There is a need to produce effective communication, distinguishing between cues with an intrinsic nature (e.g., tenderness, convenience, taste) and those with an extrinsic one (e.g., food safety). As such Lees and Saunders (2015) accentuate that the most critical strategy for imparting assurance attributes to the buyer is through the use of product labelling.

Quality marks have been acquainted as an honest choice guide for customers, yet they are additionally a method for food control, in that the availability of the label gives confirmation about the traceability of the item to a region where it was produced as well as the utilization of an arrangement of skills (Peters-Texeira and Badrie, 2005; Reid et al., 2006). Organizations of the beef supply chain have made progress in labelling beef quality to consistently meet consumers' expectations by creating strict policies that are focused on food control measures such as certifications, inspection indicators, production processes and traceability of the product to where it was produced (Tatum, 2015). Countries such as Australia, Canada, United States and Europe have developed grading systems that assists in conveying information about the quality of the product to consumers. For example, carcasses and beef cuts produced by youthful, steers and heifers are stratified into quality grades being: AAA, AA, A, "Prime, Choice, Select, Standard, Commercial, Utility and Cutter". (Reicks, 2006; Angulo and Gil, 2007; Watson et al., 2008; Polkinghorne and Thompson, 2010)

In South Africa, there is a great difference with these countries. In spite of the fact that customers are conscious about quality and food safety of beef products, their perception and preferences towards the control measures differ significantly depending on their socioeconomic characteristics and information they process (Berges et al., 2015). Quality grades and beef labelling are not extensively applied in SA the companies that have developed them, have done so in response to foreign market demands. Vermeulen and Biénabe (2007) corroborate the fact that consumers to a great extent use basic quality and convenience characteristics to choose or purchase a fresh food product in a retail outlet. 
Many international studies focusing on the beef market have reported on meat attributes and willingness to pay. Some of these attributes include certification of product origin, traceability, processes, no uses of hormones and antibiotics, price, fat content, cholesterol, artificial ingredients and safety. For instance, Prinsloo et al. (2012) found that packaging and food label information influence consumers' purchase decisions throughout the consumer decision process and that these influences have become particularly intricate in recent years.

Scozzafava et al. (2013) analysed the Italian consumer preferences for beef using the choice model approach to assess consumer behaviour. The results highlight the crucial importance of beef cut in the final choice, and reaffirm the central role played by the country of origin labelling (COOL). On the contrary, breed information and price marginally affect the final purchasing decision.

Sriwaranun et al. (2013) investigated the factors affecting consumers' willingness to pay a premium price for organic products. Results display that respondents are willing to pay a premium price of $88 \%$ for Chinese kale, $51 \%$ for jasmine rice and $51 \%$ for organic pork respectively.

Berges et al. (2015) examined consumers' perceptions in Argentina and identified factors that helped explain consumers' willingness to pay for different attributes related to safety of the beef products, including a hypothetical hygiene certification in handling and retailing. Consumers were willing to pay for fresh meat attributes such as personalized attention in a butcher counter, the presence of a "safety certification" in the place of purchase and the bright red colour on the product.

Lewis et al. (2017) evaluated German and British consumer willingness to pay for beef labelled with food safety attributes. Results showed that British consumers had the lowest WTP for beef from Argentina and German consumers had the lowest WTP for beef from Great Britain. In both the nations, the hormone-free label was the highly preferred label by consumers and those who considered food safety issues to affect their meat consumption patterns.

Most studies have mainly focused on international countries, where beef sold in the market is labelled with all necessary food safety information, while very little research has been done in Africa where there are a lot of food scandals and crises (Owusu-sekyere, 2014; Mabhera, 2015).

In environmental economics literature, lifestyles and socioeconomic characteristics including age, gender, occupation, income, education and household size can all have an effect on the willingness to pay, preferences and buying patterns of consumers on all food products. Among the work that highlights the influence of willingness to pay with socioeconomic characteristics, focusing on beef the following may be mentioned.

Angulo et al. (2005) evaluated consumers' willingness to pay a price premium for certified beef and results showed that age and income had positive and significant effects. Also, respondents who frequently bought beef were more willing to pay a premium for certified beef. However, education did not have any significant effect.

Lyford et al. (2010) assessed the effect of consumer demographics and meat consumption preferences on willingness to pay for beef quality grades, showing that older consumers were more likely to pay more for beef quality than younger consumers, whereas income, number of children in the house, number of adults in the house, main grocery purchaser, occupation, and gender did not have significant effects on WTP.

Alinda et al. (2016) determined consumer willingness to pay for quality beef in Uganda, reporting that income and beef attributes such as fat content, bone content, colour of the lean and fat influenced the willingness to pay for quality beef.

\section{Materials and Methods}

\section{Data sources, types and sampling methods}

The study was conducted in Polokwane Municipality of Limpopo province. This municipality is the largest one and a major economic centre, as well as the most urbanised and has the highest population size of 628999 (STATS SA, 2015), which indicates a high potential for beef consumption. Primary data were used in this study and a sample of 150 respondents was collected using a two-stage stratified sampling method, based on the income stratification of respondents in the municipality. For the first stage, the areas were purposefully sampled: a total of 8 areas were considered in the survey for this study: 3 areas from low income group, 2 areas from middle income group and 4 areas from high income group. At the second stage, households were randomly selected from the various areas

A structured contingent valuation questionnaire with both open and close ended questions served as a key survey instrument used to interview the consumers. The first section provided information on socioeco- nomic characteristics of respondents; such as age, gender, ethnicity, education, employment status, level of income and household size. The second section contained Likert scales questions on consumers' preferences on product safety and quality, product characteristics, safety concerns and purchasing behaviours. The final section contained a scenario and questions on WTP for graded beef. The scenario described in detail the product and the hypothetical market. Willingness to pay questions were designed with a double bounded dichotomous choice format, where the consumer is given the initial bid. If the consumer is willing to accept the first bid, a second or follow up bid which is higher is proposed. The follow up bid was different between the respondents. In cases where the respondent was not willing to accept the first bid, a lower follow up bid was then given. The choice of the first bid and the second or follow up is the most important element in the setup of the dichotomous choice survey; hence, the open-ended format was used on the pilot survey to come up with the starting bids.

\section{Empirical model used}

Contingent valuation method (CVM) is an analytical tool commonly used to reveal the public's WTP to protect non-marketed resources, such as recreation, wildlife, and environmental quality (Lin et al., 2002). In examining the viability of a new product, factors such as production cost and consumer demand for the product must be taken into consideration (Kimenju and De Groote, 2005). Studies which have evaluated products or services that are not yet on the market asked consumers to value their products contingent upon market availability of the product (Owusu, 2009). This helps to determine the consumer demand or willingness to pay (WTP) for such products in a hypothetical market situation. WTP is the maximum amount of money a consumer would be willing to pay for the new product. CVM is the most widely used method and consists of asking respondents how much they would be willing to pay for a specific change or improvement compared to the current situation using an open-ended or close-ended question (Lusk and Hudson, 2004). In an open-ended question the respondent is asked to declare the amount they would be willing to pay, whereas in close- ended the respondent is asked if they would be willing to pay for the new product or not (Owusu, 2009).

There are around four main elicitation methods that exist in CVM, namely openended format, bidding game, payment cards and dichotomous choice. 
For this study, the double bounded dichotomous choice format was chosen. In double bounded dichotomous choice questions, the respondent is presented with two bids, a first bid (B) for the good in question and a follow up bid contingent upon the previous one. For example, if the respondent gives a positive response to the initial bid, a higher second bid is offered $\left(\mathrm{B}^{H}\right)$ since the respondent has a higher WTP than the initial bid, and if the response to the first bid is negative it is followed by a lower bid $\left(\mathrm{B}^{L}\right)$ since the first bid is greater than the respondents' WTP. The bid amounts to elicit WTP are determined both by considering the ongoing prices in the market and the results of the pilot survey (Loureiro et al. 2002; Jerop, 2012).

Building from the dichotomous choice format, there are four possible combinations of responses to the questions: (1) "yes" to both bids (YY), (2) "no" followed by a "yes" (NY), (3) "yes" followed by a "no" $(\mathrm{YN})$, and (4) "no" to the first and second bid (NN).

The WTP function is represented as: $W T P=\alpha-\rho B+\lambda^{\prime} Z+\varepsilon$

The model expressed in the terms of the probability of purchasing graded beef to a bid amount can be specified as follows:

$$
\operatorname{Pr}\{W T P \leq B\}=\Phi\left(\alpha-\rho B+\lambda^{\prime} Z\right)
$$

where, WTP: the minimum acceptable price discount for graded beef; $B$ : the bid price (in percent discount) offered to graded beef, $\mathrm{Z}$ : a set of observable characteristics for consumers, $\Phi$ : a cumulative distribution function, $\alpha, \rho$ and $\lambda$ : unknown parameters $\varepsilon$ : a random term.

The probability that a given respondent is willing to pay for graded beef is given by;

(1) the YY group, $\operatorname{Pr}\left\{B^{H} \leq W T P\right\}=1-\Phi(\alpha$ $-\rho B+\lambda^{\prime} Z$

(2) the YN group, $\operatorname{Pr}\left\{\mathrm{B} \leq \mathrm{WTP} \leq \mathrm{B}^{H}\right\}=\Phi$ $\left(\alpha-\rho B^{H}+\lambda^{\prime} Z\right)-\Phi\left(\alpha-\rho B+\lambda^{\prime} Z\right.$

(3) the NY group, $\operatorname{Pr}\left\{\mathrm{B}>\mathrm{WTP} \leq \mathrm{B}^{L}\right\}=\Phi$ $\left(\alpha-\rho B+\lambda^{\prime} Z\right)-\Phi\left(\alpha-\rho B^{L}+\lambda^{\prime} Z\right)$,

(4) the NN group, $\operatorname{Pr}\{B>W T P\}=\Phi(\alpha-$ $\left.\rho B^{H}+\lambda^{\prime} Z\right)$,

Joining the probabilities of the four outcomes under the assumption of utility maximization, the log-likelihood function for a sample takes the form:

$\ln L=\sum\left\{\mathrm{I}_{\mathrm{d}=1} \ln \left[\Phi\left(\alpha-\rho \mathrm{B}+\lambda^{\prime} \mathrm{Z}\right)\right]+\mathrm{I}_{\mathrm{d}=2} \ln \right.$ $\left[\Phi\left(\alpha-\rho \mathrm{B}+\lambda^{\prime} \mathrm{Z}\right)-\Phi\left(\alpha-\rho \mathrm{B}^{\mathrm{L}}+\lambda^{\prime} \mathrm{Z}\right)\right]+$
$\mathrm{I}_{\mathrm{d}=3} \ln \left[\Phi\left(\alpha-\rho \mathrm{B}^{\mathrm{H}}+\lambda^{\prime} \mathrm{Z}\right)-\Phi(\alpha-\rho \mathrm{B}+\right.$

$\left.\left.\left.\lambda^{\prime} Z\right)\right]+\mathrm{I}_{\mathrm{d}=4} \ln \left[1-\Phi\left(\alpha-\rho \mathrm{B}+\lambda^{\prime} \mathrm{Z}\right)\right]\right\}$

where $\mathrm{I}_{d=1}, \mathrm{I}_{d=2} \mathrm{I}_{d=3}$ and $\mathrm{I}_{d=4}$ are binary variables with 1 representing the occurrence of that particular result, and 0 otherwise. The parameters are estimated by maximizing the log-likelihood function of the four discrete outcomes (Jerop, 2012). The mean WTP was calculated by $\alpha / \rho$.

The logit model was used to assess the dependence of WTP on socioeconomic characteristics. The logit model was used to assess the dependence of WTP on socioeconomic characteristics. The model is as shown in Equation below:

$\mathrm{WTP}=\beta_{0}+\beta_{1}$ Age $+\beta_{2}$ Gen $+\beta_{3}$ Ethn + $\beta_{4}$ Edulevel $+\beta_{5}$ Marstat $+\beta_{6} \mathrm{HH}+\beta_{7}$ Emp + $\beta_{8}$ Inc $+\beta_{9}$ Awa $+\beta_{10}$ Fre $+u_{i}$

\section{Results and Discussion}

\section{Consumers' socioeconomic charac- teristics}

The results of the socioeconomic characteristics of beef consumers sampled are as presented in Table 1. This is based on households in the Polokwane municipality. From the total sample, $63.3 \%$ of the respondents were females and $36.7 \%$ were males. The high percentage of females may be attributed to the fact that women are mostly involved in grocery buying and food preparations; an observation consistent with the South African culture. $47 \%$ of the respondents are single, followed by married respondents $(44 \%)$, while the divorced and widowed were the least represented categories $(8.6 \%)$. This implies that single and married people should be targeted. About $76.7 \%$ of consumers interviewed were African, while Whites and Coloureds were represented by less than $30 \%$.

Most of the respondents had tertiary education $(59.3 \%)$, about $30.7 \%$ of the respondents had high school education, while $6.0 \%$ had primary education, and $4.0 \%$ of the respondents had no formal education. This indicates that most of the consumers who specialize in the purchase of beef have attained tertiary education. This could be because some form of education is needed to fit into the urban way of life.

The results shown in Supplementary Table S2 show that, the mean household size is 5.28 members in each household with a standard deviation of 2.31. The mean age of respondents is 37.05 years with a standard deviation of 11.56 . The average household income per month is 14480.15 Rands and a high number of respondents were employed.

\section{Awareness of beef grades}

To assess if respondents were aware of the grading or classification system in the South African meat industry, respondents were asked if they had knowledge about the quality and safety of beef, which control measures assured safety and quality and if they understood the classification marks on meat as the form of coloured marks. Results show that slightly more than half of the interviewed beef consumers (53\%), perceived knowledge of the classification system or marks on some cuts of the meat (Supplementary Figure S1). This is attributed to the fact that the interviewed purchase beef at supermarkets where price is the only differentiating attribute and there are little or no standards for safety and quality, and consequently must depend on the use of classification marks on beef to decrease the danger of purchasing meat that is not safe. Results could also be attributed to the high literacy level of the respondents. Even though the results state that consumers are aware of the system, there is still a small increasing awareness on grading systems as compared with the other countries (Vermuelen et al. 2015). Respondents indicated the lack of availability of labels to show grades or classification, as a primary reason that they did not know or understand the classification or grading system.

Table 1. Socioeconomic characteristics of consumers.

$\begin{array}{cc}\text { Variable } & \text { Frequency } \\ & \text { Percentage } \\ (\%)\end{array}$

Gender

$\begin{array}{lll}\text { Male } & 55 & 36,7 \\ \text { Female } & 95 & 63,3\end{array}$

\begin{tabular}{lcc} 
Educational level & & \\
No formal education & 6 & 4 \\
Primary school & 9 & 6 \\
High school & 46 & 30,7 \\
Tertiary education & 89 & 59,3 \\
\hline
\end{tabular}

Marital status

\begin{tabular}{lcc} 
Marital status & & \\
Single & 71 & 47,3 \\
Married & 66 & 44 \\
Divorced & 2 & 1,3 \\
Widowed & 11 & 7,3 \\
Ethnicity & & \\
African & 115 & 76,7 \\
Coloured & 18 & 12 \\
White & 17 & 11,3 \\
\hline
\end{tabular}

\section{Employment status}

\begin{tabular}{lcc} 
Employed & 104 & 69,3 \\
Unemployed & 46 & 30,7 \\
\hline
\end{tabular}




\section{Consumer preferences regarding safe and quality beef}

There is a continuing need to examine consumers' preferences for quality beef attributes to properly develop and use those characteristics as the industry attempts to provide consumers with easy and convenient meats. Bone and fat content in the meat, fat colour, meat colour and juiciness were beef quality attributes that consumers accounted as their most preferred attributes (Table 2). Respondents (87\%) showed a strong preference for beef with less fat, less bones, white fat, tender and slightly red meat. This is supported by Labuschagne et al. (2011) who found that SA consumer traditionally prefer beef that is tender. When asked to account for their choice of preferences, most consumers revealed that fat content was the most important underlying characteristics for beef quality. It is also perceived as indicators of beef tenderness and palatability, which increase utility derived from beef consumption. The bone content is important because respondents explained that they would want to maximise utility by paying for what they can eat. The remaining respondents (13\%) preferred juiciness and appearance (red colour). While these are considered as important qualities in analysing preferences for beef consumers, they appear to be somewhat less important in this study.

To determine which food safety scares consumers are concerned about while procuring beef products these days, the respondents were requested to rate five given concerns. Figure 1 shows that animal disease is the most threatening issue for beef consumers, followed by salmonella, hormones and fat or cholesterol. Consumers seem to be less affected by antibiotics used in the beef industry.

Table 2. Consumer preference for quality beef.

\begin{tabular}{lc} 
Beef attributes & $\%$ of consumers \\
Fat content & 49 \\
Bone content & 17 \\
\hline Fat colour & 21 \\
Lean colour & 5 \\
\hline Beef juiciness & 8 \\
\hline
\end{tabular}

Table 3. Distribution of consumer willingness to pay.

\begin{tabular}{lcc}
\hline WIIP & Frequency & Percentage \\
Willing to pay & 97 & 64.67 \\
Not willing to pay & 53 & 35.33 \\
\hline Total & 150 & 100 \\
\hline
\end{tabular}

It is understood by the respondents that the beef marketing chain can be risky: 53\% of the respondents want their beef to be free from physical objects as a sign of safety, followed by microbes (bacteria, E. coli, etc) $40 \%$ and lastly chemicals (pesticides, drugs, etc.) $7 \%$. Overall, most of the respondents believed that the meat in the market place (grocery stores and butcheries) is safe for consumption and of great quality (Supplementary Figure S2).

\section{Purchasing behaviour of consumers}

Findings indicate that most of the respondents $(60.7 \%)$ purchase beef at a monthly basis, followed by $31.3 \%$ who purchase on a weekly basis. This could be attributed to higher prices of beef when compared to its substitutes. About $61.7 \%$ of the respondents purchased beef at the supermarket (Supplementary Table S3) because the acquired product is packaged. The butchery was selected second, because respondents were considering factors such as freshness, bulkiness and knowledge and trustworthiness of the butcher. Lastly, approximately $10 \%$ of the respondents purchase beef from local shops, hawkers and others self-produce.

Price $(86.6 \%)$ and convenience (66\%) are some of the reasons why South African consumers have a habit of purchasing meat in accessible retail places, including supermarkets, hypermarkets and small grocery stores. In South Africa fresh meat is mostly sold through supermarkets where consumers enjoy doing their household shopping in one retail outlet. Butcher shops are also very popular for the purchase of meat in South Africa and this channel appeals mainly to consumers who prefer purchasing fresh meat in bulks and who value the knowledge which only trained and experienced butchers provide, such as the quality of the meat $(83.3 \%)$ and making sure the meat is safe $(83.3 \%)$.

As shown in Figure 2 the importance of information available on the beef package was ranked by consumers as follows: price, grade or class and size/quantity of the product were the most important labels followed by quality inspection or certification indicator. These findings are consistent with those of Peters-Texeira and Badrie (2005) and Prinsloo et al. (2012), who found that consumers had higher interest of nutritional information on food packages. Slightly lower attention was given to nutritional information and brand name. Producer's identity was found to be the last information in which consumers were interested. These results show that beef front-pack labels in SA should include nutritional information, storage instruction, quality inspection, price, size and grade or class.

\section{Empirical results}

\section{Willingness to pay for graded beef}

The distribution of respondents willing to pay for graded beef is shown in Table 3 . Of all consumers, $64.67 \%$ were willing to do so and the remaining $35.33 \%$ were not willing to pay anything.

Initially the respondents were asked if they would pay more for beef. Respondents who accepted were additionally asked if they would be willing to pay for graded beef at a higher price. The actual or base price of beef was R42.20/kg.

The bid sets were randomly distributed to the questionnaire. These initial and second bids were obtained during the pilot survey. Over half of the respondents would be willing to pay more although the percentage decreased with the level of the premium. Respondents given a 5\% premium, only $68 \%$ were willing to pay. For respondents

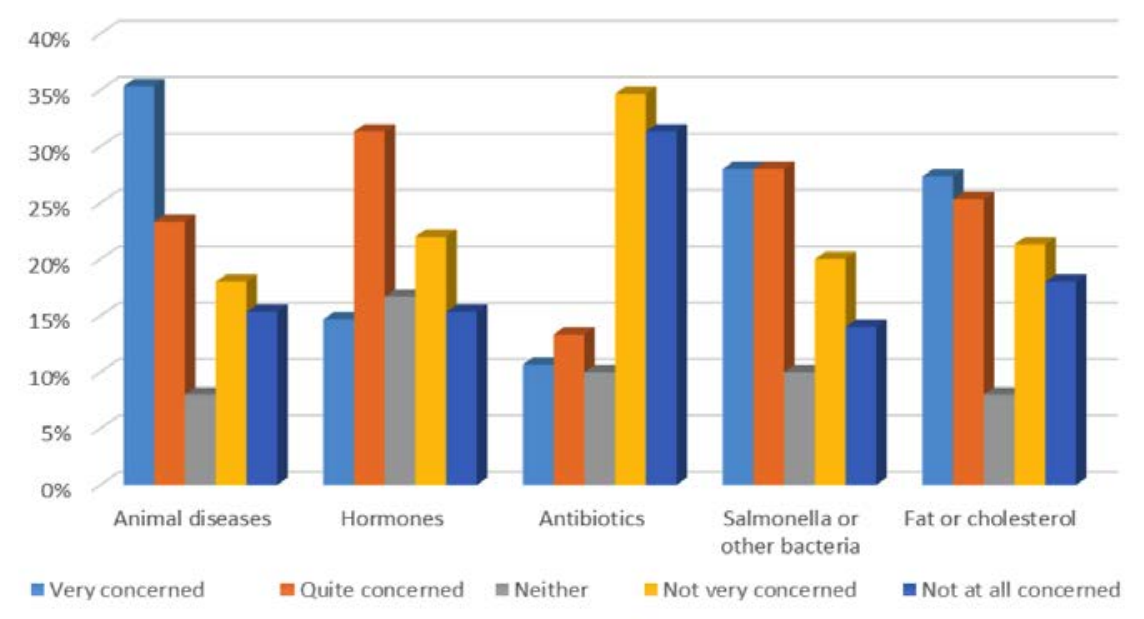

Figure 1. Consumers' safety concerns. 
given a $25 \%$ premium, only $56.7 \%$ were willing to pay. This is consistent with economic theory because the amount of the respondents willing to pay decreased as the bid they were asked to pay increased.

Respondents who rejected the initial bid $(35.3 \%)$ were presented with a lower bid (discount), also at different percentage to the actual price of beef. Of those offered a discount of $5 \%, 33.3 \%$ were willing to pay. One hundred percent (100\%) of respondents with a $25 \%$ discount accepted the bid (Table 4). To evaluate the mean WTP empirically, the logit model explaining WTP without consumer characteristics $\left(\lambda_{\mathrm{i}}=0\right)$ was estimated. Table 5 shows estimated mean WTP for the graded beef considered in the study. As previously mentioned, the mean willingness to pay can be derived from the $\alpha / \rho$ ratio, where $\alpha$ is the coefficient of the intercept term and $\rho$ is the coefficient of the bid. Therefore, mean $\mathrm{WTP}=\alpha / \rho=\mathrm{R} 48.97 / \mathrm{kg}$. The positive mean WTP for graded beef is expected, given studies in other countries (Chung et al. 2012). Results show that consumers would be willing to pay an increase of $16.04 \%$ for graded beef, as opposed to normal beef with no differentiation. It is important for all the stakeholders in the beef industry to consider this attribute as a tool for differentiation. This is supported by Berges et al. (2015) who found out that the mean willingness to pay for purchasing certified beef with the presence of "safety certification" label, was approximately $20 \%$ higher than the current price. Sriwaranun et al. (2013) indicated that respondents were willing to pay a premium price of $88 \%$ for organic products. Lewis et al. (2017) also found that consumers were willing to pay more for safety attributes in Germany.

\section{The effects of socioeconomic characteris- tics on WTP}

To analyse the effects of different characteristics on willingness to pay, the abovementioned equation was estimated. The model included a total of 10 variables and only four were found to significantly influence WTP.

The results in Table 6 reveal that the gender had an expected positive and significant effect on the willingness to pay for graded beef at $1 \%$. This means that female would pay more for graded than males; indeed, being responsible for buying groceries and cooking for the entire household, women would be willing to give out more of their income to keep the household healthy. The marginal effect of 0.013 implies that being female increases the probability of the respondent to pay more for graded beef by $1.3 \%$. The positive sign was expected and significant at $1 \%$ indicat- ing that female consumers are likely to pay high premiums than male consumers.

The coefficient of income showed significance at $5 \%$ and had a positive sign, implying that consumers were willing to pay more as their income increased. This finding agrees with Alinda et al. (2016), who reported that income influenced the willingness to pay for quality beef. The marginal effect indicates that having a higher income level increases willingness to pay by $2.3 \%$. Beef is a highly valuable food item for which the market price remains rel-

atively higher compared to other foods. Willingness to prioritise expenditure on beef will therefore increase with increase in income. Results shows an unexpected negative sign on the coefficient of age and a significant effect of $10 \%$. A one-year increase from the mean reduces the probability of the respondent's willingness to pay by $0.4 \%$. This indicates that older respondents are not willing to pay for graded beef when compared to younger consumers. The results indicate that, the youth who still have more years to live, for all things being

Table 4. Consumer response to different premium and discount levels.

\begin{tabular}{lcccccc} 
Bid & WIP & \multicolumn{5}{c}{ Response (\%) } \\
\multirow{2}{*}{ Premium } & Yes & 68.0 & 65.8 & 79.8 & 55.0 & 56.7 \\
& No & 32.0 & 34.2 & 11.2 & 45.0 & 44.3 \\
\multirow{2}{*}{ Discount } & Yes & 33.3 & 54.5 & 80.0 & 80.3 & 100.0 \\
& No & 66.7 & 45.5 & 20.0 & 19.7 & 0.0 \\
\hline
\end{tabular}

Table 5. Estimates for the double bounded dichotomous choice model.

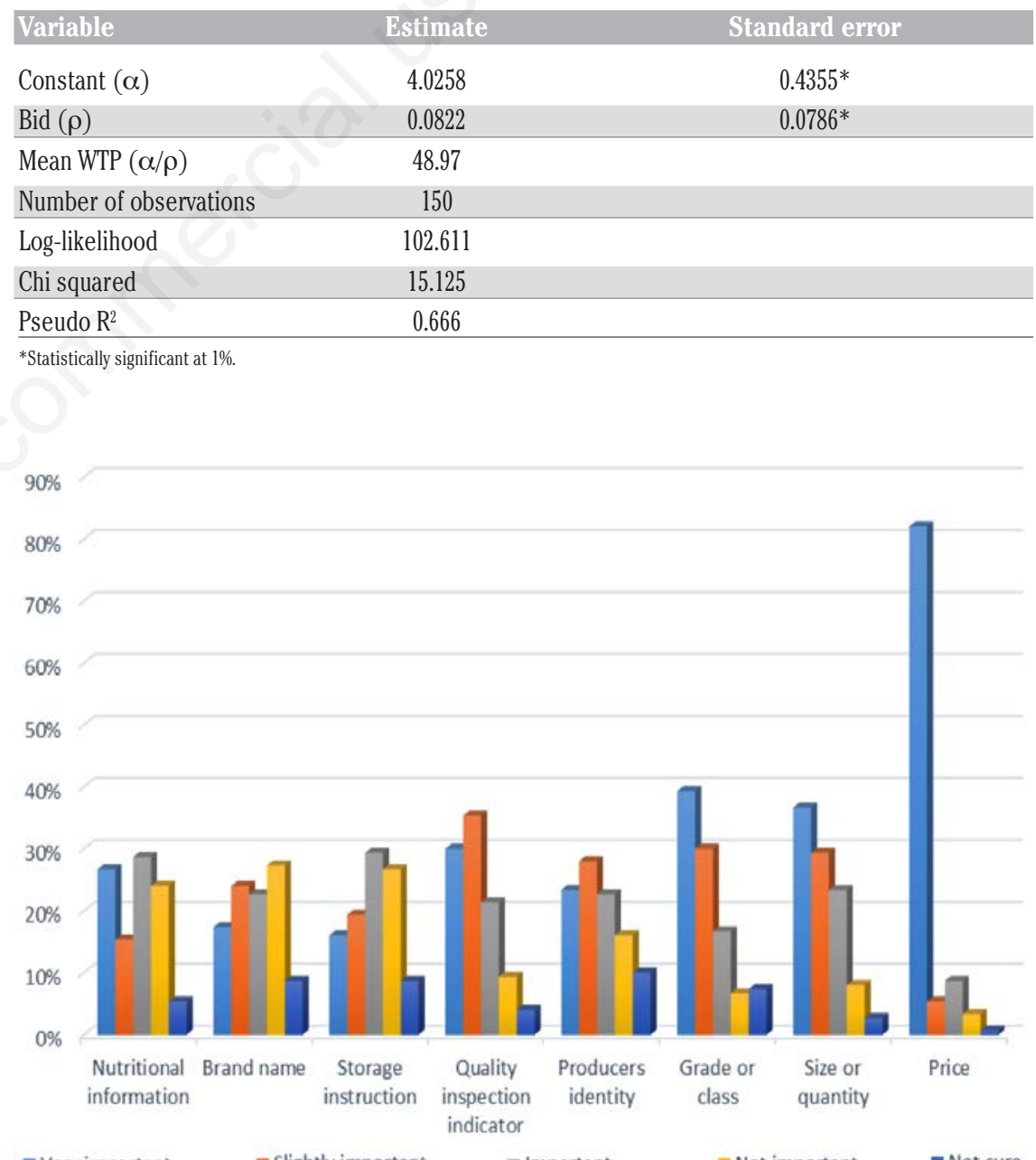

EVeryimportant =Slightly important $\quad$ Important Not important

Figure 2. Importance of information on beef labels. 
equal are likely to be cautious of the quality and safety of the food they consume as opposed to the aged who have lived their youthful age without concern to the safe measures to what they consume. This is supported by Owusu-sekyere (2014), who indicated that consumer characteristics such as age and income significantly influenced preferences and willingness to pay for beef products.

The coefficient for household size variable was negative and showed a significant effect of $10 \%$ on willingness to pay for quality beef. This finding implies that an additional member in the household reduces the probability of respondents' WTP by $1.4 \%$. This means that there is a negative correlation between household size and willingness to pay. The higher the household size, the less likely the willingness to pay more for graded beef. The reason might be that in larger households the disposable income per person decreases, therefore less willing to pay more. This finding differs from a study by Radman et al. (2012), who found that household size was the most vital and significant factor that influenced and determined the willingness to pay.

\section{Conclusions}

Heightened awareness on food-related safety issues, knowledge on the link between health and eating habits, consumers' changing food demands as well as elevated standards of living have contributed to the increasing needs for ethical food production systems from all over the world.
Generally, consumers are progressively becoming concerned on where and how food products are produced. Understanding the preferences of consumers regarding quality and safe beef and the WTP for graded beef is therefore relevant. This study examined consumers' preferences and willingness to pay for graded beef. Using the contingent valuation, beef attributes and socioeconomic factors that are important in explaining consumer willingness to pay for graded beef were determined and their coefficients estimated. Primary data were collected, and a two-stage stratified sampling method was used to identify 150 beef consumers to participate in the study.

Findings reveal that consumers prefer less fat, less bones, white fat and slightly red colour meat. Also, they prefer beef products to be labelled with price, grade/class, size or quantity of the product and lastly quality inspection or certification indicator. Over half of the respondents $(53 \%)$ were aware of grading or classification systems and their major source of information was through the butcher's information. Small-scale producers and processors should consider these attributes to implement differentiation to stimulate further demand.

Consumers are willing to purchase graded beef because it will be fully labelled, indicating the grades which will help them choose cuts suitable for their type of preparations and reveal that the product is free from chemicals, drugs, etc. The results reveal that consumers are willing to pay extra if they think that the product also provides greater quality and health benefits.

Table 6. Logit results of socioeconomic factors influencing consumer willingness to pay.

\begin{tabular}{lccc} 
Variable description & Coefficient & Standard error & Marginal effects \\
Constant & 3.2958 & 0.2873 & - \\
Gender & 1.222 & $0.0016^{* * *}$ & 0.0131 \\
\hline Income & 0.087 & $0.050^{* *}$ & 0.0229 \\
Age & -0.139 & $0.065^{*}$ & -0.004 \\
\hline Education & 0.106 & 0.557 & 0.0157 \\
Household size & -0.231 & $0.069^{*}$ & -0.0143 \\
\hline Ethnicity & 0.429 & 0.109 & 0.0191 \\
Marital status & -0.216 & 0.527 & -0.104 \\
\hline Employment & 0.033 & 0.061 & 0.0175 \\
Frequency of purchase & 0.035 & 0.138 & 0.003 \\
\hline Awareness of beef grades & 0.137 & 0.167 & 0.059 \\
Number of observations & 150 & & \\
\hline Log-likelihood & 98.224 & & \\
Chi squared & 20.095 & & \\
\hline Pseudo $\mathrm{R}^{2}$ & 0.578 & & \\
\hline$* * * * *$ are significant at 10\%,5\% and 1\% respectively & & \\
\hline
\end{tabular}

Approximately $65 \%$ of the respondents are willing to pay an increase of $16.04 \%$ over the current price of beef with no differentiation. About $35 \%$ of the respondents were not willing to pay anything, as they feel the extra cost for graded beef is unreasonable and too high. This could be an opportunity for investments in beef front-pack label industry in Polokwane, since more educated consumers are likely to be more informed on beef quality standards. Moreover, they are aware of nutrition content and concerned with labelled and graded beef.

The information produced by respondents prove that a grading or classification scheme could achieve the objective of promoting or marketing of beef by using the marking or labelling of quality marks (grading information) on beef up to the point of retail, this can satisfy consumer choices with different levels of willingness to pay. Grading with respect to quality attributes would therefore make beef sales at differentiated prices possible. Ultimately, it would enhance sales volumes and returns for beef producers, processors and traders in the value chain. Graded beef could also facilitate the development of beef exports.

Among socioeconomic characteristics, age, gender, income and household size significantly influence WTP. Elderly consumers were not willing to pay for graded beef when compared to younger consumers, while those with higher level of income per month and few members in the household have higher WTP than those with little income and bigger household size. The general population is a good target for this campaign, but it is important to reach out to the young consumers, females and high-income earners because they showed positive WTP for graded beef. It is therefore recommended that investors use selective targeting of socioeconomic characteristics to develop a strong market for quality characteristics and food safety of beef products. As shown in the results, when income increases the respondents were willing to pay more for graded beef.

\section{Implications and recommendations}

Implications from the study extend to three levels explicitly: farming, meat sector and government. Subjects deal with quality and marketing issues. Firstly, at farm level, it was indicated that challenges to be met deal with increasing production efficiency and producing quality and intrinsically safe meat through animal welfare and environment friendly production methods. For future growth of production, farmers need to practise stringent production practises, controls and standards as set by the govern- 
ment and meat sector. Secondly, at the meat sector, changes in consumer needs and demands for safety and quality guarantees are major constrains. For competitive advantage, role players need to produce beef that is healthy, of good quality and convenient for consumers. Restoring the image of meat and providing consumers with assurance are also recognized as priorities. The meat sector should also use selective targeting of socioeconomic characteristics to develop a strong market for quality characteristics and food safety of beef products. Thirdly, the government has a role of protecting consumers through providing education related to potential health risks and benefits and establishing clear rules and regulations to benefit all role players in the meat chain. Future research on the relationship between changing consumer behaviour and meat consumption patterns could provide additional valuable insights into new business opportunities.

\section{References}

Alinda F, Kavoi MM, Mugisha J, 2013. Consumer willingness to pay for quality beef in Kampala, Uganda. JAGST 17: 59-77.

Angulo AM, Gil JM, 2007. Risk perception and consumer willingness to pay for certified beef in Spain. Food Qual Pref 8:1106-11.

Angulo AM, Gil JM, Tamburo L, 2005. Food Safety and Consumers' Willingness to Pay for Labelled Beef in Spain. J Food Prdts Mktg 11:89-105.

Berges M, Casellas K, Rodriguez R, Errea D, 2015. Willingness to Pay for Quality Attributes of Fresh Beef. Implications on the Retail Marketing. J. Int. Assoc. Agric. Econ 34:360-9.

Bergevoet R, Van Engelen A, 2014. The Kenyan meat sector opportunities for Dutch agribusiness. LEI Wageningen UR (University \& Research centre), LEI Report 2014-032.

Chung C, Briggeman CB, Han S, 2012. Willingness-to-Pay for Beef Quality Attributes: A Latent Segmentation Analysis of Korean Grocery Shoppers. J. of Agric. and Appl .Econ. 44: 447459.

Dhivya R, 2014. Food safety and quality: A factor analysis approach to consumer perception. Int J Comm Bus Mgt 7:2632.

Hall SC, 2012. Beef Consumption in Curitiba, Brazil: Willingness to Pay for Sustainable Production. MSc thesis, Faculty of North Carolina State University.
Jaffee S, 2004. "From Challenge to Opportunity: The transformation of the Kenyan fresh vegetable trade in the context of emerging food safety and other standards." Agriculture and Rural Development Discussion Paper 1, World Bank. Washington, DC.

Jongen WMF, Meulenberg MTG, 2005. Innovation in Agri-food Systems. 2nd edn. Wageningen Academic Pub.

Jerop R, 2012. Consumer willingness to pay for dairy goat milk in Siaya County, Kenya. Master of Science Degree in Agricultural and Applied Economics of Egerton University.

Kimenju SC, De Groote H, 2005. Consumers' Willingness to Pay for Genetically Modified foods in Kenya. Paper presented at the 11thInternational Congress of the EAAE (European Association of Agricultural Economists), The Future of Rural Europe in the Global Agri-Food System, Copenhagen, Denmark, August 24-27, 2005.

Kimenju SC, De Groote H, 2008. Consumer willingness to pay for genetically modified food in Kenya. Agric Econ 38:3546.

Kumm KI, 2002. Sustainability of Organic Meat Production under Swedish Conditions. Short Comm Agric Ecosys Envir 8: 5-101.

Labuschagne A, Louw A, Ndanga L, 2010. A Consumer-Orientated Study of the South African Beef Value Chain. Contributed Paper presented at the Joint 3rd African Association of Agricultural Economists (AAAE) and 48th Agricultural Economists Association of South Africa (AEASA) Conference. Cape Town, South Africa.

Latvala T, 2010. Risk, information, and trust in the food chain: factors explaining consumer willingness to pay. J Food Syst Dynamics 1: 230-24.

Lees N, Saunders C, 2015. Maximising export returns (MER): communicating New Zealand's credence attributes to international consumers. Research report No. 334. http://www.lincoln .ac.nz/aeru. (Accessed, 12 June 2016).

Lewis KE, Grebitus C, Colson G. Hu W, 2017. German and British consumer willingness to pay for beef labelled with food safety attributes. J Agric Econ 68:451-70.

Lin W, Somwaru A, Tuan F, 2010 Consumers' willingness to pay for biotech foods in china: a contingent valuation approach. J Agrobiotech Mgt Econ 9:227-40.

Liana M, Radam A, Yacob MR, 2010. Consumer perception towards meat safety: confirmatory factor analysis. Int J Econ Mgt 4:305-18.

Loureiro ML, Hine SE, 2002. Discovering niche markets: a comparison of consumer willingness to pay for local (Colorado-grown), organic and GMOfree products. J Agric Appl Econ 34:257-80.

Lusk JL, Hudson D, 2004. Willingness-toPay Estimates and Their Relevance to Agribusiness Decision Making. Rev Agric Econ 26:152-69.

Lyford C, Thompson J, Polkinghorne R, Miller M, Nishimura T, Neath K, Allen $\mathrm{P}$, Belasco E, 2010. Is willingness to pay (WTP) for beef quality grades affected by consumer demographics and meat consumption preferences. Austr Agribus Rev 18:1-17.

Mabhera S, 2015. Consumer perceptions and values on beef quality: implications on beef markets. Master of Science in Agricultural Economics, Department of Agricultural Economics and Extension, Faculty of Science and Agriculture. University of Fort Hare, Eastern Cape.

Markiewicz K, 2010. The economics of meeting future protein demand. Business Economics thesis, Wageningen University.

Owusu MA, 2009. The assessment of market potential and marketing prospects of organic fruits and vegetables in Kumasi metropolis of Ghana. MPhil thesis, Department of Agricultural Economics, Agribusiness and Extension, Kwame Nkrumah University of Science and Technology, Kumasi, Ghana.

Owusu V, Anifori MO, 2013. Consumer willingness to pay a premium for organic fruit and vegetable in Ghana. Int Food Agribus Mgt Rev 16:67-86.

Owusu-sekyere E, 2014. Consumer preferences and willingness to pay for beef attributes in Ghana. Unpublished M.sc thesis (Agric. Economics), Department of Agricultural Economics; Faculty of Natural and Agricultural Sciences, University of the Free State, Bloemfontein.

Peters-Texeira A, Badrie N, 2005. Consumers' perception of food packaging in Trinidad, West Indies and its related impact on food choices. Int $\mathrm{J}$ Cons Stud 29:508-14.

Polkinghorne RJ, Thompson JM, 2010. Meat standards and grading: a world view. Meat Sci 86:227-35.

Prinsloo N, Van der Merwe D, Bosman M, Erasmus A, 2012. A critical review of the significance of food labelling during consumer decision making. J Fam Ecol Cons Sci 40:83-98.

Radman M, Camanzi L, Kolega A, 2005. 
Preferences and buying behavior of beef consumers in Tuscany. J Cent Euro Agric 6: 99-106.

Reicks A, 2006. Consumer motivations and the impact of brand on purchasing preferences of fresh beef. Doctor of Philosophy thesis, Faculty of Animal Science, Texas Tech University.

Reid LM, O’Donell CP, Downey G, 2006. Recent Technological Advances for the Determination of Food Authenticity. Trends Food Sci Tech 17:344-53.

Sanderson K, Hobbs JE, 2006. Traceability and process verification in the Canadian beef industry. Report prepared for Canfax Research Services. Department of Agricultural Economics, University of Saskatchewan.

Schroeter C, 2005. Consumer attitudes towards food safety risks associated with meat processing. MSc thesis, Kansas State University.

Schutte NS, 2006. Techniques for Developing Emotional Intelligence. In Stough C., Saklofske, D and Hansen, K. (Eds.). Research on Emotional Intelligence: International Symposium 2005 (pp 77-88). Melbourne Australia. Tertiary Press.

Scozzafava G, Casini L, Contin C, 2014. Analysis of Italian consumer preferences for beef. New Medit 1:66-80.

Soji Z, Chikwanda D, Chikwanda AT, Jaja
LF, Mushonga B, Muchenje V, 2015. Relevance of the formal red meat classification system to the South African informal livestock sector. South Afr J Anim Sci 45:263-4.

Sriwaranun Y, Gan C, Lee M, Cohen D, 2013. Consumers' willingness to pay for organic products in Thailand. Faculty of Commerce Working Paper no.4. Lincoln University, New Zealand.

Statistics South Africa (Stats SA), 2015. General Household Survey 2015.

Tatum JD, 2015. Recent trends: beef quality, value and price. Available from: http:/www.cabpartners.com/articles/ne ws/217/ChoiceSelectWhitePaper.pdf. (Accessed, 14 September 2016).

Uwamaliya B, 2014. Assessment of consumer awareness and preferences for quality certification and origin-labelling in food salads, Kigali, Rwanda. Unpublished M.sc thesis (Agric. Economics), Department of Agricultural Economics; Faculty of Agriculture, University Nairobi.

Van Wezemael L, Verbeke W, de Barcellos MD, Scholderer J, Perez-Cueto F, 2010. Consumer perceptions of beef healthiness: results from a qualitative study in four European countries. BMC Publ Health 10:342.

Vermeulen H, Bienabe E, 2007. What about the food quality turn' in South Africa?
Focus on the organic movement development. Poster Paper prepared for presentation at the 105th EAAE Seminar, "International Marketing and International Trade of Quality Food

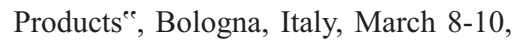
2007.

Vermeulen H, Biénabe E, 2010. The quality turn in South Africa: insights from a comprehensive investigation into the food quality behaviors, perceptions and knowledge of South African consumers with a focus on middle and upper socioeconomic groups. In AAAE third conference/AEASA 48th conference. Cape Town, South Africa, September 19-23. African Association of Agricultural Economists (AAAE) \& Agricultural Economics Association of South Africa (AEASA).

Vermeulen H, Schönfeldt HC, Pretorius B, 2015. A consumer perspective of the South African red meat classification system. South Afr J Anim Sci 45:34080.

Watson R, Polkinghorne R, Thompson JM, 2008. Development of the Meat Standards Australia (MSA) prediction model for beef palatability. Austr J Exp Agric 48:1368-79. 